\title{
POTENSI PEMANFAATAN PUNA DAN KAMERA HIPERSPEKTRAL DALAM PENINDAKAN LADANG GANJA DI DAERAH TERPENCIL
}

\author{
Ade Purwanto ${ }^{1}$ \\ Pusat Teknologi Industri Pertahanan dan Keamanan Badan Pengkajian dan Penerapan Teknologi \\ (BPPT) \\ Email: ade.purwanto@bppt.go.id
}

\begin{abstract}
Cannabis has been a major problem regarding drugs abuse in the world, especially in the South East Asia. This study offers a potential solution to increase the effectiveness of Cannabis control in remote areas using time and costeffective method by applying RPAS and a hyperspectral camera in the program. RPAS will be the platform to airborne the hyperspectral camera in order to identify potential Cannabis plantation so that a measured appropriate handling could be executed. BPPT has developed several tactical RPASs with an operating radius range up to $150 \mathrm{~km}$ and a flight endurance up to 6 hours. The platform is capable of carrying mission-specific payloads and obtaining data in real-time and at low cost. Plants identification was determined using Hyperspectral camera with wavelength between 400 to $900 \mathrm{~nm}$. Indoor and outdoor measurement was done. The study shows that the hyperspectral camera was capable of classifying target plant out of the others. The study shows that combination of RPAS and hyperspectral technology would be able to determine the particular spectral signature of the cannabis with the highest result compared to other methods available in Indonesia.

Keywords: Cannabis, hyperspectral, RPAS
\end{abstract}

\begin{abstract}
ABSTRAK: Penyalahgunaan Ganja telah menjadi salah satu masalah utama mengenai narkoba di dunia, terutama di Asia Tenggara. Studi ini menawarkan solusi potensial untuk meningkatkan efektivitas pengendalian Ganja di daerah terpencil dengan menggunakan metoda, waktu dan biaya yang efektif dengan melibatkan teknologi PUNA dan kamera hiperspektral dalam program tersebut. PUNA digunakan untuk menerbangkan sensor hiperspektral untuk kemudian melakukan identifikasi lading Ganja, sehingga dapat dilakukan penanganan yang tepat. BPPT telah berhasil mengembangkan beberapa PUNA taktikal dengan jangkauan radius operasi hingga 150km dan ketahanan terbang hingga 6 jam. Platform ini mampu membawa payload spesifik untuk misi dan mendapatkan data secara real-time dan berbiaya rendah. Identifikasi tanaman dilaksanakan menggunakan sensor hiperspectral milik BPPT dengan panjang gelombang antara 400 sampai $900 \mathrm{~nm}$. Pengambilan data dalam ruangan tertutup dan di ruangan terbuka juga telah dilakukan. Hasil studi tersebut menunjukkan bahwa kamera hiperspektral mampu mengklasifikasikan tanaman yang telah ditentukan dari tanaman lainnya. Studi tersebut menunjukkan bahwa kombinasi teknologi PUNA dan hiperspektral ini akan dapat menentukan tanda spektral tertentu dari ganja dengan hasil yang paling optimal dibandingkan dengan berbagai metoda lain yang ada di Indonesia.
\end{abstract}

Kata kunci: ganja, hiperspektral, PUNA

\section{PENDAHULUAN}

$\mathrm{G}$ anja menurut KBI, adalah tumbuhan yg daunnya dapat memabukkan dan sering dihisap bersama rokok. Dikenal juga sebagai Mariyuwana dan dalam terminology latinnya adalah Cannabis sativa [1]. Dalam dua dekade terakhir, penyalahgunaan narkoba, terutama ganja telah mengalami peningkatan yang sangat signifikan, Di tingkat global, WHO dalam situsnya menuliskan bahwa ganja sejauh ini merupakan obat-obatan terlarang yang paling banyak dibudidayakan, diperdagangkan, dan disalahgunakan. Sekitar 147 juta orang, yaitu $2,5 \%$ dari populasi dunia, mengonsumsi ganja[2]. Sedangkan gambaran dari penanganan ganja ini bisa dilihat dari grafik penyitaan ganja oleh apparat di seluruh dunia, bahkan titik tertingginya menyentuh angka hingga hingga 8.000 ton ganja yang telah disita [3].

\footnotetext{
${ }^{1}$ Pusat Teknologi Industri Pertahanan dan Keamanan, Badan Pengkajian dan Penerapan Teknologi (BPPT)
} 


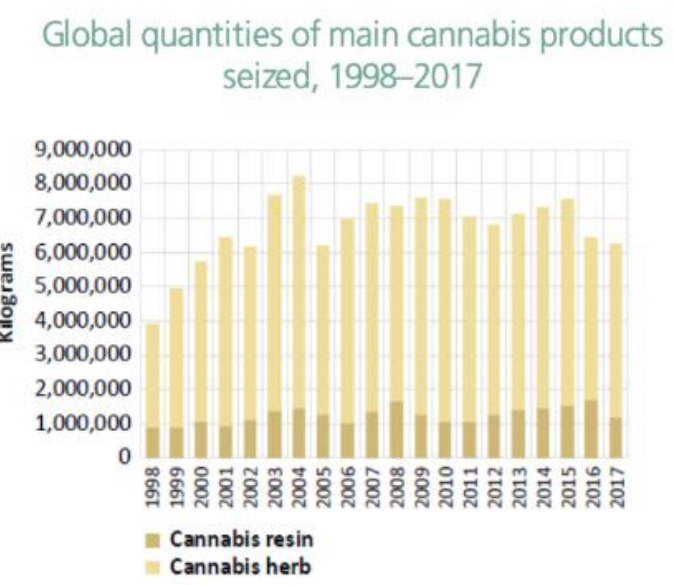

— Gambar 1. Grafik penyitaan ganja dunia 1998-2017[3]

Di tingkat Asean, mengacu pada table 1 dari ASEAN Drug Monitoring report yang terbit 2016, tingkat prevalensi Ganja bisa mencapai 3.5\% di Kamboja dan lebih khusus di Indonesia, angka prevalensinya sebesar $0.5 \%$ di tahun 2010 [4]. Artinya, untuk Indonesia saja, $0.5 \%$ dari 300 juta penduduk Indonesia atau sekitar 15 juta penduduk yang menyalahgunakan Ganja. Lebih dalam lagi di Indonesia, data BNN menyebutkan bahwa dalam tahun 2019 saja, BNN telah melakukan sebelas (11) kali pemusnahan ladang ganja dengan nilai total berat ganja basah mencapai 108 ton. Dengan berbagai data ini maka Indonesia sudah sepatutnya lebih serius lagi dalam penindakan penyalahgunaan tanaman ganja ini.

Tabel 1. Prevalensi tahunan tanaman Ganja di ASEAN [4]

\begin{tabular}{|l|c|c|c|c|}
\hline \multicolumn{1}{|c}{ Country } & Age & Annual prevalence (\%) & Year & Sources \\
\hline Brunei Darussalam & $15-64$ & 0.02 & 1996 & UNODC: WDR2006 \\
\hline Cambodia & $15-64$ & 3.5 & 2003 & UNODC: WDR2012 \\
\hline Indonesia & $15-64$ & 0.5 & 2010 & UNODC: WDR2012 \\
\hline Lao PDR & $15-64$ & 0.88 & 2008 & UNODC: WDR2012 \\
\hline Malaysia & $15-64$ & 1.6 & 2003 & UNODC: WDR2012 \\
\hline Myanmar & $15-64$ & 0.94 & 2005 & UNODC: WDR2012 \\
\hline The Philippines & $15-64$ & 0.74 & 2008 & UNODC: WDR2012 \\
\hline Singapore & $15-64$ & 0.004 & 2004 & UNODC: WDR2006 \\
\hline Thailand & $12-65$ & 1.2 & 2007 & UNODC: WDR2012 \\
\hline Vietnam & $15-64$ & 0.3 & 2002 & UNODC: WDR2012 \\
\hline
\end{tabular}

Kendala utama yang dihadapi oleh BNN adalah lokasi ladang - ladang ganja ini yang sangat terpencil dan sulit dijangkau, terutama di daerah pedalaman provinsi NAD. Hal ini membutuhkan beberapa strategi teknologi untuk meningkatkan efektifitas penindakan. Beberapa opsi yang ada adalah dengan pemantauan via satelit, penggunaan platform pesawat udara berawak atau menggunakan pesawat udara nir-awak (PUNA). Satelit mempunyai kelemahan dengan mahalnya data terkini, pesawat berawak terkendala mahalnya biaya operasi sedangkan pesawat nir-awak terkendala dengan prestasi terbang dan kemampuan angkut payload yang sangat terbatas dalam mendeteksi ladang ganja. Beberapa sensor yang bisa digunakan untuk mendeteksi ladang ganja baik di satelit ataupun pesawat adalah Electro Optical (secara manual), Multispectral dan Hyperspectral (secara otomatis dengan post-processing data). 
Sebagai lembaga riset dalam negeri, BPPT menawarkan solusi berupa potensi kombinasi PUNA dengan prestasi terbang yang sangat baik dan payload hyperspectral camera untuk melakukan deteksi ladang ganja di daerah terpencil, dengan syarat telah terdapat database berupa data spektral dari tanaman ganja di lapangan dengan berbagai umurnya. Hyperspectral camera bekerja dengan cara menangkap signature dari setiap objek pada rentang hyperspectral kamera tersebut, yang kemudian data ini bisa diolah menjadi produk citra. Produk citra bisa bervariasi mulai dari pergeseran lahan dan perubahan topografinya (apabila diambil dalam rentang waktu tertentu), kesehatan vegetasi yang diamati, perbedaan antar objek dalam frame data, dan lain sebagainya. Untuk pemantauan ladang ganja, data yang perlu diolah adalah deteksi perbedaan signature tanaman ganja terhadap berbagai vegetasi yang lain yang ada di frame yang tertangkap kamera.

\section{METODE}

Klasifikasi tanaman menggunakan pesawat tanpa awak atau drone atau RPAS (remotely piloted aircraft system) telah dicoba dilakukan di beberapa studi. Seperti penggunaan Multispektral pada optocopter[5], menggabungkan data satelit dan RPAS agar bisa didapat dimensi temporal[6], Hexacopter dan SVM untuk klasifikasi menggunakan snapshot hyperspectral imager[7] dan beberapa tulisan yang lain. Sedangkan klasifikasi menggunakan pesawat berawak telah dicoba oleh BPPT bekerja sama dengan ERSDAC Jepang antara lain pada [8] dan [9]. Teknik klasifikasi ganja dengan hyperspectral telah juga dipelajari pada beberapa penelitian seperti [10]-[16]. Kesemuanya menggunakan data satelit atau ground measurement. Pendekatan berbeda yang penulis tawarkan adalah potensi pemanfaatan drone fix-wing untuk mengambil data kawasan yang dicurigai sebagai ladang ganja, dan mengolah data spektral dari data yang didapat, untuk kemudian dilakukan klasifikasi tanaman ganja dari tanaman yang lainnya. Keuntungan yang didapat dari menggunakan platform fixwing adalah, cakupan daerah yang bisa lebih luas dari quadrotor, waktu pengamatan yang fleksible tidak seperti dengan menggunakan satelit.

BPPT memiliki pesawat udara tanpa awak dengan performa yang sangat baik, dan yang penulis paparkan dalam artikel ini adalah PUNA Alap - Alap yang mempunyai prestasi terbang yang sangat bagus dan telah mendapatkan sertifikasi dari IMAA untuk bisa terbang di kawasan udara yang bersinggungan dengan pesawat yang lain. Spesifikasinya adalah :

$\begin{array}{ll}\text { Ketinggian terbang maksimum } & : 10,000 \mathrm{ft} / 3048 \mathrm{~m} \\ \text { MTOW } & : 30 \mathrm{Kg} \\ \text { Tipe Payload } & : \text { Gimbal Camera } \\ \text { Berat Payload } & : 3 \mathrm{~kg} \\ \text { Radius operasi } & : 100 \mathrm{Km} \text { (LOS) } \\ \text { Endurance } & : 6 \mathrm{jam}\end{array}$

Platform alap - alap ini membawa playload berupa kamera hyperspectral yang diterbangkan untuk mengambil data spectral dari target pengamatan.

Untuk klasifikasi spektral, spesifikasi kamera hyperspectral BPPT adalah dengan tipe SHARK dari Corning yang mempunyai detil sebagai berikut:

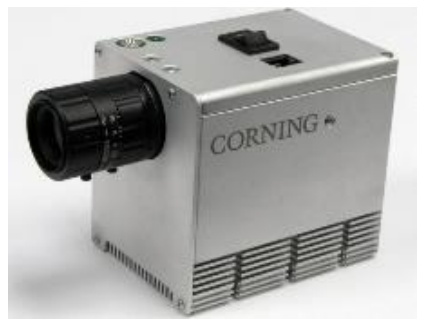

Gambar 2. Corning MicroHSI 410 SHARK 
Tabel 2. Spesifikasi Corning MicroHSI 410 SHARK milik BPPT

\begin{tabular}{|c|c|}
\hline Sensor Type & Push-broom Line Imaging Spectrometer \\
\hline Spectrograph & Solid Block Offner \\
\hline Grating & Diamond-Ruled High Efficiency Reflective Blazed \\
\hline FPA Detector & CCD/CMOS hybrid 1408 spatial pixels \\
\hline Effective Pixel Size $-2 x$ binned & $11.7 \mu \mathrm{m}$ \\
\hline Effective Array Size $-2 x$ binned & 704 spatial x 155 spectral \\
\hline Focal Length, $f / \#$ & $16 \mathrm{~mm}, \mathrm{f} / 1.4$ standard \\
\hline Full Fov & 29.5 degrees ( $516 \mathrm{mrad}$ ) standard \\
\hline IFOV & $366 \mu \mathrm{rad}$ standard \\
\hline Spectral Range & $400 \mathrm{~nm}-1000 \mathrm{~nm}$ \\
\hline Spectral Bin Size (per pixel) & $2 \mathrm{~nm}$ \\
\hline Maximum Frame Rate & $>300 \mathrm{~Hz}$ (profile dependent) \\
\hline Data Readout & 12-bit \\
\hline Ins & GPS + Mems IMU + Kalman filtered solution \\
\hline Size (standard lens, processor, data storage, INS) & $5.37^{\prime} \times 3.44^{\prime \prime} \times 2.77^{\prime \prime}$ with lens $\left(3.77^{\prime} \times 3.44^{\prime \prime} \times 2.77^{\prime \prime}\right.$ without lens) \\
\hline Weight (standard lens, data storage, INS) & $1.5 \mathrm{lb} .(0.68 \mathrm{~kg})$ \\
\hline Power Consumption (complete system) & <19W@12VDC \\
\hline Etendue & 50 steradian um ${ }^{2}$ \\
\hline
\end{tabular}

Kamera ini adalah tipe push-broom, yaitu kamera yang melakukan pengambilan data dengan cara scanning sepanjang jalur FOV-nya. Kamera pada umumnya adalah snapshot, yaotu pengambilan gambar setiap frame dengan jeda waktu tertentu. Kamera push-broom mempunyai keunggulan bahwa post-processing data tersebut lebih ringan dari tipe snapshot. Pada push-broom, hasil data tidak perlu lagi dilakukan mosaicking atau penggabungan berbagai gambar. Teknologi Push-broom juga mempunyai resolusi yang jauh lebih tinggi dikarenakan exposure yang lebih lama terhadap target. Lensa yang digunakan pada pushbroom juga tidak mempunyai lengkung yang biasanya ada pada tipe snapshot. Sedangkan kekurangannya adalah terkadang terjadi waterfall-effect, yaitu gambar yang didapat tidak lurus dan membentuk fenomena seperti air terjun, dan hal ini perlu dilakukan koreksi dengan pergerakan pesawat pada sumbu $\mathrm{x}$ dan $\mathrm{y}$, sehingga kelokan pada gambar bisa dikoreksi menjadi gambar yang lurus. Dengan pergerakan pesawat fix-wing yang selalu bergerak maju, tidak melakukan hovering, kamera tipe push-broom sangat cocok untuk pengambilan data.

Untuk pembuktian kemampuan klasifikasi dari SHARK, telah dilakukan pengambilan data pada ruangan terkendali (dark room) dengan data yang diambil menggunakan sumber cahaya berupa lampu wolfram dengan daya 60 watt yang ditempatkan pada jarak 1 meter dari objek. Kamera digerakkan di hadapan objek dengan jarak $1 \mathrm{~m}$, dengan sudut elevasi dari cahaya $20^{\circ}$. Kamera harus digerakkan, mengingat jenis sensor dari SHARK adalah berupa pushbroom. Objek ditempatkan di atas kertas putih dan kertas tersebut ditempatkan di atas light absorbent sheet. 

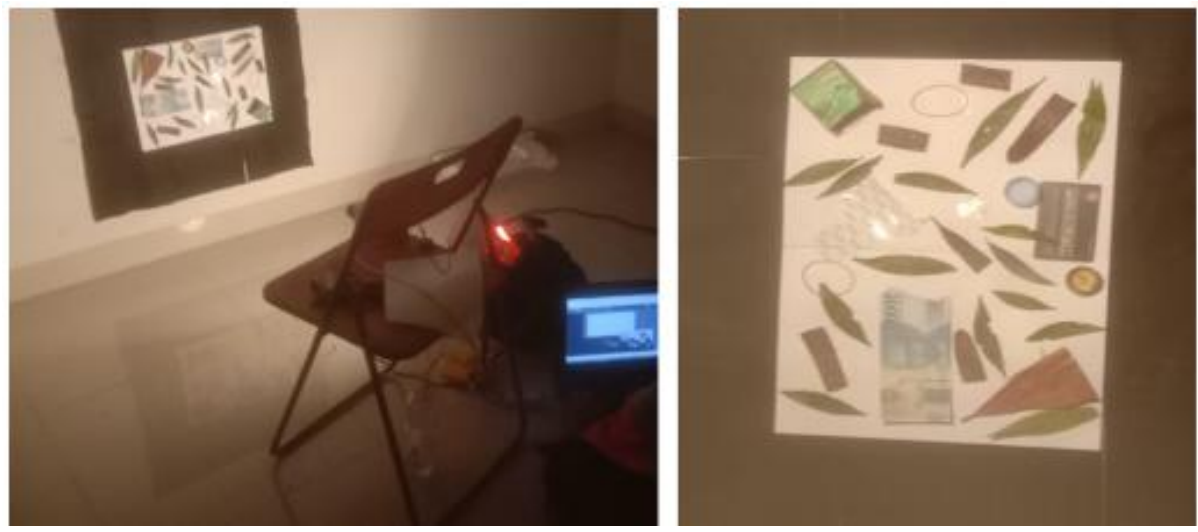

Gambar 3. Proses pengambilan data diambil pada ruang gelap (kiri) dan data hasil kamera RGB (kanan)

\section{HASIL DAN PEMBAHASAN}

Kamera hyperspectral milik BPPT telah diujicoba di lingkungan terkendali dan mampu menghasilkan klasifikasi yang baik. Pada data hyperspectral, pixel data adalah gabungan dari 300 pixel pada spektrum yang berbeda. Hal ini disebut sebagai pixel-cube. Pixel-cube ini yang kemudian dianalisa dengan cara dilakukan plot pada sumbu z dari setiap pixel yang ada. Semakin besar data yang diproses, semakin berat post-processing untuk melaukan plot pada setiap pixel data tersebut. Pada push-broom camera, data processing yang terjadi lebih ringan dikarenakan tidak perlu ada proses mosaicking sebelum plot spectral. Setelah setiap pixel-cube teridentifikasi kemudian dilakukan klasifikasi dari setiap pixel untuk membedakan masing - masing benda berdasarkan spectral signature masing - masing pixel.

Hasilnya adalah, setiap spektral dari benda yang diujikan menghasilkan data sesuai dengan ekspektasi. Hasil dari spectral imager SHARK menunjukan bahwa kamera ini mampu untuk menampilkan spectral profile dari 400nm hingga $1000 \mathrm{~nm}$ dengan baik, seperti pada gambar 4. Profil spektral dari daun hijau menunjukan adanya feature dari daun yang sehat dengan serapan pada wavelength $550 \mathrm{~nm}$ hingga mendekati $700 \mathrm{~nm}$, dan hal ini menunjukan adanya aktifitas dan struktur klorofil pada daun tersebut. Sedangkan untuk daun yang telah mati, serapan dari wavelength dengan panjang gelombang seperti di atas telah hilang, dan hal ini menunjukan tidak adanya aktifitas klorofil di dalam daun tersebut. Signature seperti ini yang akan kemudian menjadi input untuk klasifikasi setiap objek pada data yang didapat.
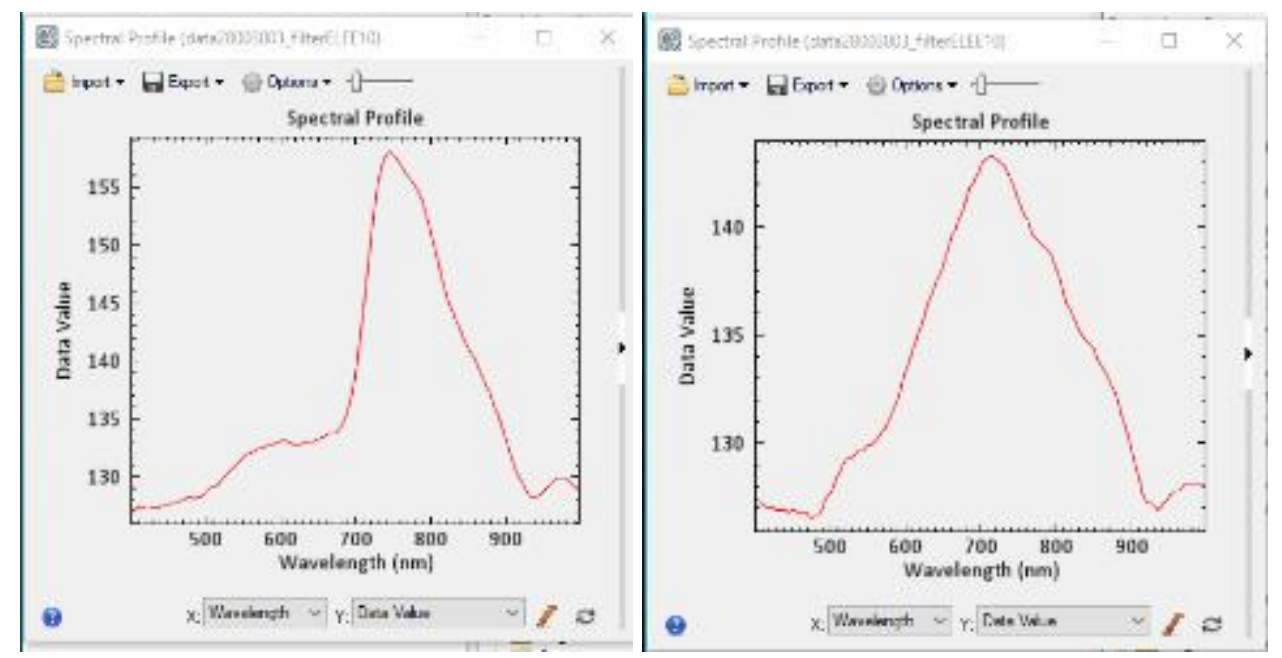

Gambar 4. Spectral Profil daun hijau (kiri) dan Spectral Profil daun kering (kanan) 
Kemudian klasifikasi dicobakan menggunakan software ENVI, menggunakan fiture machine learning berupa SVM Classifier. Training data didapatkan dari salah satu pixel daun hijau yang masih segar yang dipilih sebagai objek yang diketahui. Hasilnya adalah, seluruh daun hijau berhasil dikenali dengan baik. Sedangkan objek selain dari target daun hijau, tidak diklasifikasikan sehingga terlihat pada false color hanya daun hijau saja yang secara konsisten dikenali oleh algoritma yang digunakan. Berikut ini adalah flowchart dari SVM Classifer dari ENVI [17].

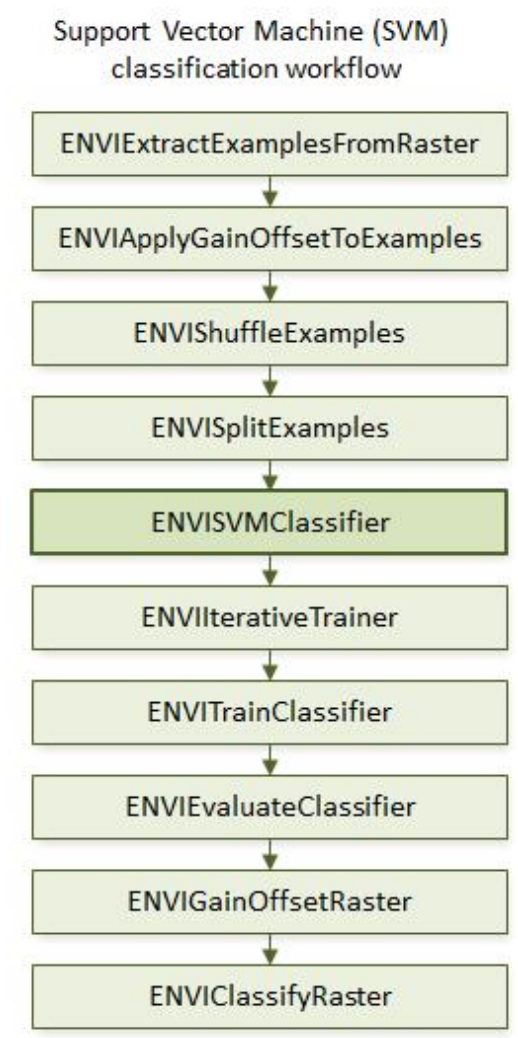

Gambar 5. Alur kerja secara umum menggunakan SVM Classifier

Klasifikasi SVM yang dipilih adalah menggunakan kernel Radial Basis Function (RBF) dengan cost parameter $\mathrm{C}$ dan $\gamma$ sesuai nilai default. Terlihat pada gambar 6 , hasil klasifikasi membuahkan hasil $100 \%$ daun hijau berhasil dikenali dengan baik. Sedangkan beberapa objek lain tercampur antara bayangan dengan background. Saturasi terjadi pada objek yang mengkilat atau yang mempunyai reflectance yang tinggi. Saturasi pada False Color ditandai dengan warna merah terang. Pada background munculnya saturasi adalah karena penggunaakn double-tape untuk melekatkan flannel. Bayangan dan objek lain masih tercampur pada warna biru dan tidak diidentifikasikan lebih lanjut. Hal ini dikarenakan misi klasifikasi hanyalah untuk mengidentifikasi fitur spectral signature pada daun hijau saja.

Terlihat pada daun kering, meskipun terjadi saturasi, profil spectral signature daun tersebut bisa digambarkan dengan baik, terlihat pada profil di gambar 1. Dengan melakukan pengaturan pada kernel dan penambahan pixel training, klasifikasi objek lain ini bisa dilakukan. 


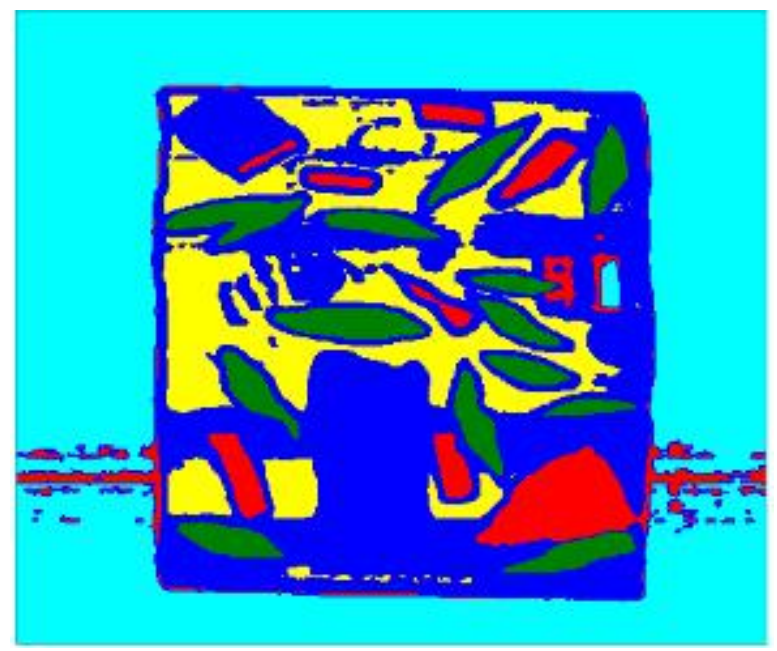

Gambar 6. Hasil klasifikasi SVM dengan satu pixel trainer

Untuk tanaman ganja sendiri, telah dilakukan berbagai penelitian mengenai spectral signature yang keluar darinya, diantaranya adalah oleh[11], [13]. Pada studi ini, data diambil menggunakan kamera AISA EAGLE, yang menemukan bahwa karakteristik spektral Ganja menunjukan keunikan pada rentang panjang gelombang $500-750 \mathrm{~nm}$.

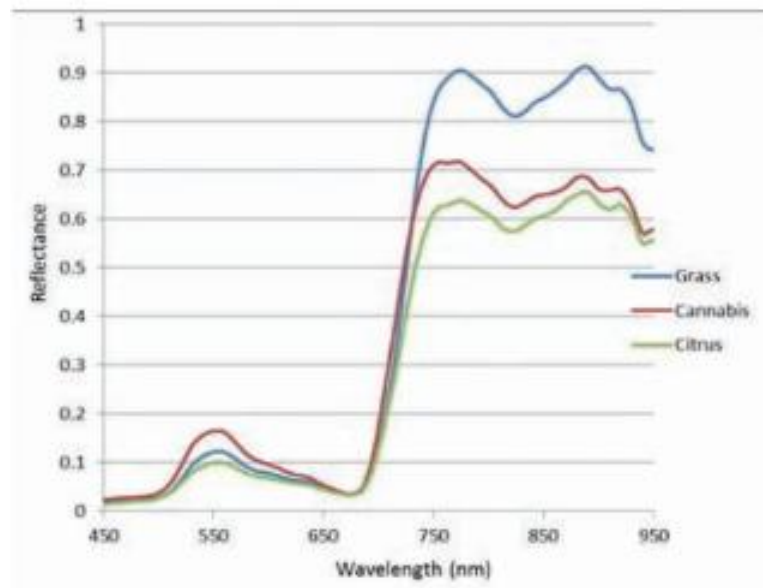

Gambar 7. Pola spectral Ganja dibandingkan dengan rumput dan jeruk oleh Azaria et.al.

Meskipun demikian, untuk kasus di Indonesia, karakteristik unik ini harus kembali diambil di lingkungan terkendali menggunakan tanaman ganja yang hidup di Indonesia pada setiap fase tumbuhnya, dan juga diambil di lingkungan sebenarnya di pedalaman provinsi NAD. Hal ini perlu dilakukan agar didapatkan database yang lengkap dan akurat sebagai training pixel untuk SVM melakukan klasifikasi. Pengambilan data untuk setiap fase tumbuh sangat penting, karena fitur dari tanaman ganja akan berubah seiring usianya. Apabila tidak didapatkan database yang lengkap maka akan ada kemungkinan klasifikasi yang mengalami kegagalan untuk menemukan ladang ganja dengan fase tumbuh di luar database yang dimiliki.

Untuk potensi operasi yang ditawarkan dari BPPT dengan payload berupa Hyperspectral adalah sebagai berikut. Spectral Imager akan dibawa oleh alap - alap untuk survei ladang ganja. Sensor ini dipasangkan pada belly Alap - Alap, sebagaimana payload yang lainnya. Alap - Alap diterbangkan dari bandara terdekat, dengan monitoring posisi dan ketinggian secara real time dari GCS (ground control station). Waypoint yang telah didesain untuk melingkupi wilayah target yang akan disisir kemudian diupload ke GUI, dan dikirimkan ke sistem kendali pesawat. Desain waypoint 
adalah agar melingkupi daerah - daerah perkiraan BNN mengenai potensial adanya ladang ganja di daerah tersebut. Proses desain waypoint dapat dilakukan iterasi apabila terdapat potensi hambatan seperti tertutup kabut atau gambar yang blur. Untuk hasil dari sensor kamera hyperspectral, data akan melakukan post-processing berupa mosaicking dan klasifikasi, sehingga data sensor yang besar ini tidak perlu dikirimkan secara real time dan cukup direkam di onboard pesawat.

Waypoint didesain menggunakan mission planner seperti ditunjukkan pada gambar 8, dengan mempertimbangkan ketinggian pesawat, kecepatan, kontur daerah dan jangkauan komunikasi GCS ke pesawat. Waypoint dievaluasi menggunakan software in loop untuk operasional alap - alap untuk melihat apakah ada potensi gangguan atau tidak. Metode ini seperti yang dijelaskan oleh [18] ketika BPPT melakukan pemetaan gunung berapi.

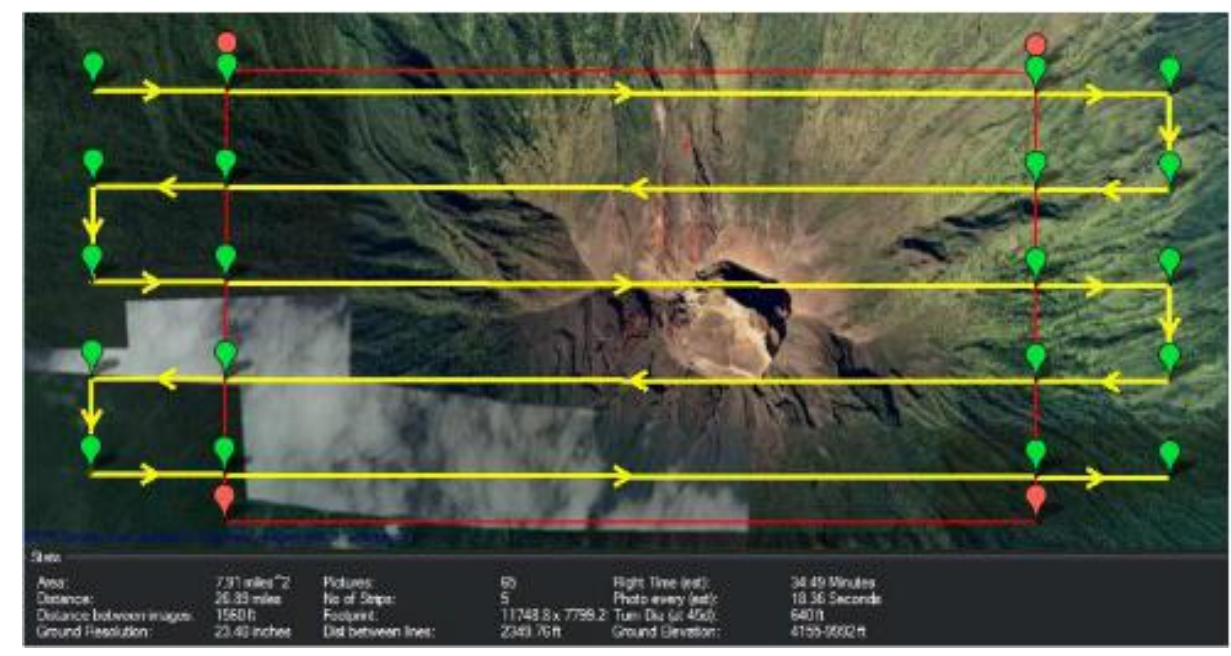

Gambar 8. Pola perencanaan penerbangan Alap - Alap untuk pemetaan

Pada saat terbang, keadaan pesawat dan setiap parameter terbangnya diamati dengan software PCC. Pesawat terbang secara autonomous dan operator pesawat memperhatikan apabila ada parameter pesawat yang di luar dari yang diharapkan, dan operator selalu siap mengambil alih kendali dalam keadaan darurat. Standar BPPT untuk pengambilan data adalah dengan ketinggian terbang 1500 feet AGL (above ground level). EFIS (Electronic Flight Instrument System) menampilkan sikap pesawat dalam Roll, Pitch dan Yaw, serta posisi ketinggian dan kecepatan pesawat. Navigasi pesawat mengikuti waypoint ditampilkan overlay di atas peta (gambar 9)

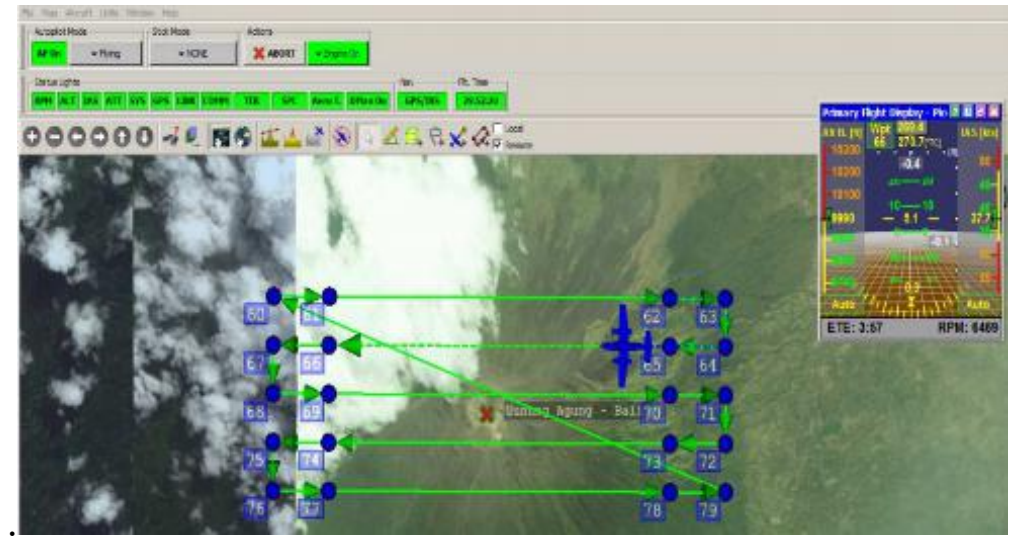

Gambar 9. Capture penerimaan data real time dari penerbangan Alap - Alap 


\section{KESIMPULAN}

Hyperspectral imager milik BPPT menggunakan teknik pushbroom, sehingga cocok untuk digunakan wahana bergerak seperti fix-wing. Koreksi yang dilakukan adalah meluruskan data waterfall dari gambar yang didapatkan agar terbentuk gabungan gambar atau mosaicking yang baik. Hal ini merupakan keuntungan menggunakan pushbroom dibandingkan dengan snapshot, yang cenderung berat pada post processing dengan mosaicking yang sangat banyak dan biasanya membutuhkan koreksi terhadap lengkung lensa. Dengan pushbroom, bisa dilakukan pengambilan data dengan daerah yang jauh lebih luas dan resolusi yang lebih tinggi dibandingkan dengan snapshot, tanpa ada distorsi oleh lensa.

SVM Classifier telah digunakan untuk melakukan klasifikasi menggunakan kamera tersebut dan hasil target klasifikasi mampu didapatkan secara konsisten. Daun hijau mampu menunjukan pola absorpsi dari aktifitas klorofil dan detil pada gelombang 500-750 nm (RED ke NIR) secara detil. Data spectral yang sangat detil, yaitu sebanyak 300 spectrum dengan jeda $2 \mathrm{~nm}$ pada setiap pixel, dapat digunakan untuk klasifikasi Ganja dari tanaman yang lainnya.

Dengan rekor berupa 1700Ha per jam maka apabila Alap - Alap diterbangkan selama 5 jam, Drone BPPT ini dapat memetakan lahan yang disinyalir sebagai ladang ganja hingga seluas lebih dari $8500 \mathrm{Ha}$. Hal ini akan sangat membantu untuk penindakan ladang ganja yang lebih luas dan lebih efektif, yaitu memastikan kondisi lapangan sebelum tim diterjunkan langsung untuk penindakan.

\section{DAFTAR PUSTAKA}

[1] Tim Penyusun KBBI, Kamus Bahasa Indonesia, xvi., vol. xvi. Jakarta, 2008.

[2] “Management of substance abuse; Cannabis," WHO, 2020. [Online]. Available: https://www.who.int/substance_abuse/facts/cannabis/en/. [Accessed: 17-Sep-2020].

[3] UNODC, Cannabis and hallucinogens, E.19.XI.8. Vienna: United Nation Publication, 2019.

[4] M. Kanato, P. Leyatikul, C. Choomwattana, and I. Thepwongsa, "ASEAN drug monitoring report 2015," ASEAN-NARCO, Bangkok, 2016.

[5] T. M. Koot, "Weed detection with Unmanned Aerial Vehicles in agricultural systems," Wageningen University, 2014.

[6] C. M. Gevaert, "Generation of STRS by combining hyperspectral UAV and multispectral satellite and hyperspectral UAV imagery for precision agriculture application.," IEEE J. Sel. Top. Appl. Earth Obs. Remote Sens., vol. 8, no. 6, pp. 31403146, 2015.

[7] T. Ishida et al., "A novel approach for vegetation classification using UAV-based hyperspectral imaging," Comput. Electron. Agric., vol. 144, no. December 2017, pp. 80-85, 2018.

[8] T. Takayama et al., "Validation of BIPLS for Improving Yield Estimation of Rice Paddy from Hyperspectral Data in West Java , Indonesia," IGARSS 2012, pp. 65816584, 2012.

[9] D. Arief et al., "Development of hyperspectral data utilization technology by using data mining method for paddy, West Java, Indonesia," 31st Asian Conf. Remote Sens. 2010, ACRS 2010, vol. 2, pp. 1259-1264, 2010.

[10] C. L. Walthall and C. S. T. Daughtry, "Development of Cannabis Spectral Signatures And Cannabis Growth Simulation Model," Beltsville, 2003.

[11] I. Azaria, N. Goldschleger, and E. Ben-Dor, "Identification of Cannabis plantations using hyperspectral technology," Isr. J. Plant Sci., vol. 60, no. 1-2, pp. 77-83, 2012.

[12] B. Thiessen, "Technical Report Satellite Detection of Cannabis sativa Outdoor Grow Operations," Ottawa, 2007.

[13] I. Azaria, N. Goldshleger, E. Ben-Dor, and R. Bar-Hamburger, "Detection of cannabis plants by hyper-spectral remote sensing means," Isr. J. Plant Sci., vol. 60, no. 1, pp. 77-83, 2012.

[14] M. Houmi, B. Mohamadi, and T. Balz, "A hyperspectral based method to detect cannabis plantation in inaccessible areas," Int. Arch. Photogramm. Remote Sens. Spat. 
Inf. Sci. - ISPRS Arch., vol. 42, no. 3, pp. 547-551, 2018.

[15] J. F. Q. Pereira, M. F. Pimentel, J. M. Amigo, and R. S. Honorato, "Detection and identification of Cannabis sativa L. using near infrared hyperspectral imaging and machine learning methods. A feasibility study," Spectrochim. Acta - Part A Mol. Biomol. Spectrosc., vol. 237, p. 118385, 2020.

[16] W. S. Holmes et al., "Classifying cannabis sativa flowers, stems and leaves using statistical machine learning with near-infrared hyperspectral reflectance imaging," I2MTC 2020 - Int. Instrum. Meas. Technol. Conf. Proc., pp. 1-6, 2020.

[17] “ENVISVMClassifier," Harrisgeospatial, 2020. [Online]. Available: https://www.harrisgeospatial.com/docs/envisvmclassifier.html. [Accessed: 17-Sep2020].

[18] Y. Guno, D. H. Budiart, and D. Raharjo, "Pemanfaatan Pesawat Udara Nir Awak (PUNA) Alap-Alap untuk Pemantauan Gunung Berapi," Maj. Ilm. Pengkaj. Ind., vol. 11, no. October, 2017. 